\title{
Simplified Comorbidity Score and Eastern Cooperative Oncology Group Performance Score Predicts Survival in Patients Receiving Organ-preserving Treatment for Bladder Cancer
}

\author{
LISA MANIG $^{1}$, LUKAS KÄSMANN ${ }^{1}$, STEFAN JANSSEN ${ }^{1}$, STEVEN E. SCHILD $^{2}$ and DIRK RADES ${ }^{1}$ \\ ${ }^{1}$ Department of Radiation Oncology, University of Lübeck, Lübeck, Germany; \\ ${ }^{2}$ Department of Radiation Oncology, Mayo Clinic, Scottsdale, AZ, U.S.A.
}

\begin{abstract}
Background/Aim: This study investigated three comorbidity scales and the Eastern Cooperative Oncology Group performance score (ECOG-PS) for survival in patients receiving local irradiation for bladder cancer. Patients and Methods: Sixty-four patients receiving organpreserving radio-chemotherapy or radiotherapy for urinary bladder cancer were retrospectively evaluated. Charlson Comorbidity Index (CCI), Simplified Comorbidity Score (SCS), Age-Adjusted Charlson Comorbidity Index (AAC) and ECOG-PS were analyzed for associations with survival. Results: Patients with a SCS of 0-7 points had a significantly better survival than those with $8-18$ points $(p=0.018)$. Fiveyear survival rates were $64 \%$ and $32 \%$, respectively. Patients with ECOG-PS of 0-1 had a significantly better 5-year survival than patients with ECOG-PS of 2-3 (64\% vs. 0\%, $p<0.001)$. For CCI $(p=0.16)$ and AAC $(p=0.49), a$ significant association with survival was not observed. Conclusion: SCS and ECOG-PS were significantly associated with survival in patients irradiated for bladder cancer and can help estimate the prognoses of these patients.
\end{abstract}

Radical cystectomy is considered standard treatment of carcinoma of the urinary bladder (1). However, since this approach is often associated with a considerable rate of surgery-related complication including perioperative death, many patients, particularly elderly patients and those with significant comorbidities are assigned to definitive radiotherapy or radio-chemotherapy with upfront

Correspondence to: Professor Dirk Rades, Department of Radiation Oncology, University of Lübeck, Ratzeburger Allee 160, D-23552 Lübeck, Germany. Tel: +49 45150045401, e-mail: rades.dirk@ gmx.net

Key Words: Comorbidity scales, performance status, bladder cancer, radiotherapy, survival prognoses. transurethral resection of the bladder (2-4). Moreover, with respect to their quality of life, a considerable number of patients refuse radical cystectomy and prefer an organpreserving approach instead. In order to choose the optimal bladder-preserving approach for an individual patient, it would be helpful to have a precise idea of the patient's survival prognosis. Such estimation would likely be supported with the knowledge of prognostic factors including comorbidity scales. The predictive value of such scales to predict the survival of cancer patients had already been shown for lung cancer patients (5-7). The present study investigated the potential prognostic role of three comorbidity scales and the Eastern Cooperative Oncology Group performance score (ECOG-PS) in patients receiving organ-preserving local radiotherapy or radio-chemotherapy for invasive carcinoma of the urinary bladder (8-11).

\section{Patients and Methods}

Sixty-four patients who had received organ-preserving radiochemotherapy or radiotherapy for urinary bladder cancer between 2000 and 2014 were retrospectively evaluated. Radiotherapy was performed with 6-18 MV photon beams from a linear accelerator after 3D-conformal treatment planning. The median dose was 59.4 Gy (range=50.4-63.0 Gy), which was delivered with conventional fractionation of 1.8 to 2.0 Gy on five consecutive days per week. Forty-six patients had received concurrent chemotherapy in addition to irradiation, which consisted of a platinum-based regimen in 28 patients, paclitaxel in 17 patients and vinflunine in 1 patient. Of these patients, 24 were female and 40 male. Median age was 76.5 years (range $=50-89$ years). Clinical tumor stage was T1 in 2 patients, T2 in 24 patients, $>\mathrm{T} 2 \mathrm{a}$ in 17 patients $\mathrm{T} 3$ in 13 patients and T4 in 8 patients, respectively. Positive lymph nodes were diagnosed in 9 patients. All but 6 patients had received at least one transurethral resection of the bladder prior to radiotherapy.

In these 64 patients, three comorbidity scales and the Eastern Cooperative Oncology Group performance score (ECOG-PS) were investigated for a potential association with survival (8-11). The 
three comorbidity scales included the Charlson Comorbidity Index (CCI, Table I), the Simplified Comorbidity Score (SCS, Table II) and the Age-Adjusted Charlson Comorbidity Index (AAC, Table III).The survival analyses were performed with the Kaplan-Meier analysis and the log-rank test (12).

\section{Results}

Patients were followed-up until death or for a median 36 months following radiotherapy in survivors. The median survival time in the entire cohort was 66 months. The points of the CCI ranged from 0 to 7 points (median 2 points).The comparison of 0-2 versus 3-7 points did not reveal a significant difference with respect to an association with survival $(p=0.16)$. The survival rates at 1 year, 3 years and 5 years of both CCI ranges are summarized in Table IV.

The range of points of the SCS was 0 to 18 with a median of 7 points. Patients achieving 0-7 points had a significantly better survival than patients with $8-18$ points $(p=0.018)$. The survival rates of both SCS ranges at 1, 3 and 5 years are shown in Table IV.

The points of AAC ranged from 2 to 10 points (median 5 points). The comparison of 2-5 versus 6-10 points did not show a significant difference in survival $(p=0.49)$. The survival rates at 1,3 and 5 years of both $\mathrm{AAC}$ ranges are given in Table IV.

In addition to the three comorbidity scales, the ECOG-PS was investigated. The median ECOG-PS was 1 (range=0-3). Patients with an ECOG-PS of 0-1 had a significantly better survival than those patients with an ECOG-PS of 2-3 $(p<0.001)$. The corresponding survival rates at 1,3 and 5 years are summarized in Table IV.

\section{Discussion}

Carcinoma of the urinary bladder is one of the less common solid tumors in adult cancer patients (13). Many patients cannot withstand radical cystectomy (14). Their prognoses can be improved with modern multi-disciplinary treatment regimens (15-21). Another important approach is the administration of personalized anticancer therapy taking into account many factors including the patient's remaining lifespan. In order to be able to have an idea of an individual patient's survival prognosis, a profound knowledge of predictive factors is mandatory. Comorbidity scales were reported to serve as indicators for survival of lung cancer patients (5-7). In the present study, three such scales plus the ECOG-PS were investigated for a potential association with the survival of patients with bladder cancer, who received bladder-preserving treatment in form of radiotherapy or radiochemotherapy with or without upfront transurethral resection.

According to the results of this study, the SCS was significantly associated with survival in this group of patients. Patients with a SCS of 0-7 points had a significantly better
Table I. Charlson Comorbidity Index (CCI) (7).

\begin{tabular}{ll}
\hline Weight & Comorbidities \\
\hline 1 Point & $\begin{array}{l}\text { Myocardial infarction, congestive heart failure, } \\
\text { peripheral vascular disease, cerebrovascular } \\
\text { disease, dementia, chronic obstructive pulmonary } \\
\text { disease, connective tissue disease, ulcer disease, } \\
\text { mild liver disease, diabetes mellitus }\end{array}$ \\
& $\begin{array}{l}\text { Hemiplegia, moderate or severe renal disease, } \\
\text { diabetes mellitus with end organ damage, } \\
\text { any tumor, leukemia, lymphoma }\end{array}$ \\
3 Points & $\begin{array}{l}\text { Moderate or severe liver disease } \\
\text { Points }\end{array}$ \\
& immune deficiency syndrome (AIDS) \\
\hline
\end{tabular}

Table II. Simplified Comorbidity Score (SCS) (7).

\begin{tabular}{ll}
\hline Weight & Comorbidities \\
\hline 1 Point & $\begin{array}{l}\text { Cardiovascular comorbidity, respiratory } \\
\text { comorbidity, neoplastic comorbidity, alcoholism }\end{array}$ \\
4 Points & Renal insufficiency \\
5 Points & Diabetes mellitus \\
7 Points & Tobacco consumption \\
\hline
\end{tabular}

survival at 1, 3 and 5 years when compared to patients with a SCS of 8-18 points. This finding agrees well with the results of the study of Colinet et al. that included 735 patients with non-small cell lung cancer, who had received different types of treatment (10). In this study, the authors developed and validated the SCS and reported it to be more informative than the CCI. Following the study of Colinet et al., other authors also investigated the value of the SCS with respect to estimating the survival of lung cancer patients (18-21). Singh et al. included 238 patients who received first-line chemotherapy for different histologic types of lung cancer (22). When comparing patients with a SCS $\leq 9$ versus $>9$, the median survival did not significantly differ between both groups. Similar results were reported from a study of 73 patients with small-cell lung cancer, when comparing SCS ranges of 0-5 points, 6-11 points and $12-17$ points $(p=0.54)$ (23). In another prospective study form Australia that included 633 patients with non-small lung cancer, a SCS $>9$ was not associated with a worse survival prognosis than a SCS $\leq 9$ (hazard ratio(HR $)=1.0 ; p=0.8)(24)$. In contrast, on multivariate 
Table III. Age-Adjusted Charlson Comorbidity Index (AAC) (7).

\begin{tabular}{ll}
\hline Weight & Comorbidities \\
\hline 1 Point & $\begin{array}{l}\text { Myocardial infarction, congestive heart failure, } \\
\text { peripheral vascular disease, cerebrovascular disease, } \\
\text { dementia, chronic obstructive pulmonary disease, } \\
\text { connective tissue disease, ulcer disease, mild } \\
\text { liver disease, diabetes mellitus }\end{array}$ \\
2 Points & $\begin{array}{l}\text { Hemiplegia, moderate or severe renal disease, } \\
\text { diabetes mellitus with end organ damage, } \\
\text { any tumor, leukemia, lymphoma }\end{array}$ \\
3 Points & $\begin{array}{l}\text { Moderate or severe liver disease } \\
\text { Points }\end{array}$ \\
$\begin{array}{l}\text { Metastatic solid tumor, acquired immune } \\
\text { point }\end{array}$ & $\begin{array}{l}\text { Each decade over the age of } 40 \text { years, up to } 4 \text { points } \\
\end{array}$
\end{tabular}

analysis of a study with 172 patients with small cell lung cancer from Taiwan, patients with a SCS $>9$ had a significantly worse prognosis than patients with a SCS $\leq 9$ (25). A significant difference was found in both patients with limited disease (hazard $\operatorname{ratio}(\mathrm{HR})=2.17 ; 95 \%$ confidence interval $(\mathrm{CI})=1.12$ 4.21) and patients with extensive disease (hazard ratio 1.74; 95\%-confidence interval 1.12-2.72). In addition, in patients with extensive disease, SCS $>9$ was associated with a worse response to anticancer treatment $(60 \%$ vs. $82 \%, p=0.02)$. Considering the contradictory results from the studies reported in the literature, the predictive value of the SCS in lung cancer patients remains unclear.

However, our present study showed a significant association between SCS and survival in patients with bladder cancer, a tumor entity with a much different histology than lung cancer. In the present study, patients with a SCS of 0-7 points had a significantly better survival prognosis than patients with a SCS of 8-18 points. Thus, patients with $0-7$ points may benefit from radiotherapy with higher total doses such as 59.4 Gy and the addition of radiosensitizing chemotherapy to achieve a better long-term locoregional control, since the risk of developing loco-regional recurrences increases with the patients' lifetime. Dose per fraction should be $1.8 \mathrm{~Gy}$ rather than $\geq 2.0 \mathrm{~Gy}$ to keep the risk of late radiation-related toxicities as low as possible. In addition to the SCS, our study demonstrated the ECOG-PS to be a significant predictor of survival. Patients with an ECOG-PS of $0-1$ had a significantly better survival than patients with an ECOG-PS of 2-3. Similar to patients with a SCS of 0-7 points, patients with an ECOG-PS of 0-1 should receive radiotherapy with a total dose of 59.4 Gy
Table IV. Comorbidity scales and the corresponding survival rates.

\begin{tabular}{|c|c|c|c|c|}
\hline & $\begin{array}{c}1 \text { year } \\
(\%)\end{array}$ & $\begin{array}{c}3 \text { years } \\
(\%)\end{array}$ & $\begin{array}{l}5 \text { years } \\
(\%)\end{array}$ & $p$-Value \\
\hline \multicolumn{5}{|l|}{ Charlson Comorbidity } \\
\hline \multicolumn{5}{|l|}{ Index $(\mathrm{CCI})$} \\
\hline 0-2 Points $(n=43)$ & 86 & 68 & 60 & \\
\hline 3-7 Points $(n=21)$ & 62 & 56 & 37 & 0.16 \\
\hline \multicolumn{5}{|l|}{ Simplified Comorbidity } \\
\hline \multicolumn{5}{|l|}{ Score (SCS) } \\
\hline 0-7 Points $(n=39)$ & 87 & 78 & 64 & \\
\hline 8-18 Points $(\mathrm{n}=25)$ & 63 & 42 & 32 & 0.018 \\
\hline \multicolumn{5}{|l|}{ Age-Adjusted Charlson } \\
\hline \multicolumn{5}{|c|}{ Comorbidity Index (AAC) } \\
\hline 2-5 Points $(n=45)$ & 82 & 65 & 67 & \\
\hline 6-10 Points $(\mathrm{n}=19)$ & 68 & 62 & 41 & 0.49 \\
\hline \multicolumn{5}{|c|}{$\begin{array}{l}\text { Eastern Cooperative Oncology Group } \\
\text { performance score (ECOG-PS) }\end{array}$} \\
\hline $0-1(n=47)$ & 87 & 72 & 64 & \\
\hline $2-3(n=17)$ & 49 & 42 & 0 & $<0.001$ \\
\hline
\end{tabular}

supplemented with concurrent chemotherapy and doses per fraction of $1.8 \mathrm{~Gy}$.

The significant prognostic role of the performance status for the survival of cancer patients has been extensively reported in the literature including patients with bladder cancer (26-28). This demonstrates some consistency of the data of our present study. One should bear in mind that retrospective studies always carry the risk of hidden selection biases. However, prospective trials are difficult to perform, because bladder cancer is an uncommon malignancy.

In conclusion, the SCS and the ECOG-PS were significantly associated with survival in patients receiving organ-preserving radiotherapy or radio-chemotherapy for bladder cancer. These scales can help physicians when aiming to estimate the survival prognoses of these patients.

\section{Conflicts of Interest}

On behalf of all Authors, the corresponding Author states that there is no conflict of interest related to this study.

\section{References}

1 Koga $\mathrm{F}$ and Kihara K: Selective bladder preservation with curative intent for muscle-invasive bladder cancer: a contemporary review. Int J Urol 19: 388-401, 2012.

2 Maebayashi T, Ishibashi N, Aizawa T, Sakaguchi M, Sato K, Matsui T, Yamaguchi $\mathrm{K}$ and Takahashi S: Radiotherapy for muscle-invasive bladder cancer in very elderly patients. Anticancer Res 36: 4763-4769, 2016.

3 Konety BR, Allareddy V and Herr H: Complications after radical cystectomy: analysis of population-based data. Urology 68: 5864, 2006. 
4 Manoharan M, Ayyathurai R and Soloway MS: Radical cystectomy for urothelial carcinoma of the bladder: an analysis of perioperative and survival outcome. BJU Int 104: 1227-1232, 2009.

5 Firat S, Byhardt RW and Gore E: Comorbidity and Karnofksy performance score are independent prognostic factors in stage III non-small-cell lung cancer: an institutional analysis of patients treated on four RTOG studies. Radiation Therapy Oncology Group. Int J Radiat Oncol Biol Phys 54: 357-364, 2002.

6 Kopek N, Paludan M, Petersen J, Hansen AT, Grau C and Høyer M: Co-morbidity index predicts for mortality after stereotactic body radiotherapy for medically inoperable early-stage nonsmall cell lung cancer. Radiother Oncol 93: 402-407, 2009.

7 Otake S, Ohtsuka T, Asakura K, Kamiyama I and Kohno M: Impact of comorbidity index on morbidity and survival in nonsmall cell lung cancer. Asian Cardiovasc Thorac Ann 24: 30-33, 2016.

8 Charlson ME, Pompei P, Ales KL and MacKenzie CR: A new method of classifying prognostic comorbidity in longitudinal studies: development and validation. J Chronic Dis 40: 373-383, 1987.

9 Charlson M, Szatrowski TP, Peterson J and Gold J: Validation of a combined comorbidity index. J Clin Epidemiol 47: 12451251, 1994.

10 Colinet B, Jacot W, Bertrand D, Lacombe S, Bozonnat MC, Daurès JP and Pujol JL: A new simplified comorbidity score as a prognostic factor in non-small-cell lung cancer patients: description and comparison with the Charlson's index. Br J Cancer 93: 1098-1105, 2005.

11 Oken MM, Creech RH, Tormey DC, Horton J, Davis TE, McFadden ET and Carbone PP: Toxicity and response criteria of the Eastern Cooperative Oncology Group. Am J Clin Oncol 5: 649-655, 1982.

12 Kaplan E and Meier P: Nonparametric estimation from incomplete observation. J Am Stat Assoc 53: 457-481, 1958.

13 Siegel RL, Miller KD and Jemal A: Cancer statistics, 2016. CA Cancer J Clin 66: 7-30, 2016.

14 Guancial EA, Roussel B, Bergsma DP, Bylund KC, Sahasrabudhe D, Messing E, Mohile SG and Fung C: Bladder cancer in the elderly patient: challenges and solutions. Clin Interv Aging 10: 939-949, 2015.

15 Jana BR and Zhou Y: Novel molecular targets for the therapy of urothelial cancer. Anticancer Res 35: 4557-4567, 2015.

16 Lea MA, Guzman Y and Desbordes C: Inhibition of growth by combined treatment with inhibitors of lactate dehydrogenase and either phenformin or inhibitors of 6-phosphofructo-2-kinase/ fructose-2,6-bisphosphatase 3. Anticancer Res 36: 1479-1488, 2016.

17 Kuo JH, Shih TY, Lin JP, Lai KC, Lin ML, Yang MD and Chung JG: Cantharidin induces DNA damage and inhibits DNA repairassociated protein expressions in TSGH8301 human bladder cancer cell. Anticancer Res 35: 795-804, 2015.

18 Kilari D, Iczkowski KA, Pandya C, Robin AJ, Messing EM, Guancial E and Kim ES: Copper transporter-CTR1 expression and pathological outcomes in platinum-treated muscle-invasive bladder cancer patients. Anticancer Res 36: 495-501, 2016.
19 Nakagawa YU, Nagaya H, Miyata T, Wada Y, Oyama T and Gotoh A: Piperazine-based alpha-1 AR blocker, naftopidil, selectively suppresses malignant human bladder cells via induction of apoptosis. Anticancer Res 36: 1563-1570, 2016.

20 Sakaguchi M, Maebayashi T, Aizawa T, Ishibashi N and Saito $\mathrm{T}$ : Clinical results for bladder cancer treated by radiotherapy without concurrent standard chemotherapy. Anticancer Res 36: 5519-5525, 2016.

21 Hancock BM, McGuire KL, Tsuji S, Reil K, Hernandez V, Giacalone MJ and Godbey WT: A single intravesical instillation of VAX014 inhibits orthotopic superficial bladder tumor implantation to increase survival. Anticancer Res 36: 6243-6248, 2016.

22 Singh N, Singh PS, Aggarwal AN and Behera D: Comorbidity assessment using Charlson Comorbidity Index and Simplified Comorbidity Score and its association with clinical outcomes during first-Line chemotherapy for lung cancer. Clin Lung Cancer 17: 205-213, 2016.

23 Kaesmann L, Janssen S, Schild SE and Rades D: Value of comorbidity scales for predicting survival after radiochemotherapy of small cell lung cancer.Lung 194: 295-298, 2016.

24 Alexander M, Evans SM, Stirling RG, Wolfe R, Officer A, MacManus M, Solomon B, Burbury K, Ball D: The influence of comorbidity and the Simplified Comorbidity Score on overall survival in non-small cell lung cancer - A prospective cohort study. J Thorac Oncol 11: 748-757, 2016.

25 Kuo YW, Jerng JS, Shih JY, Chen KY, Yu CJ and Yang PC: The prognostic value of the simplified comorbidity score in the treatment of small cell lung carcinoma. J Thorac Oncol 6: 378383, 2011.

26 Manig L, Käsmann L, Janssen S and Rades D: Predicting survival after irradiation of metastases from transitional carcinoma of the bladder. Anticancer Res 36: 6663-6665, 2016.

27 Bellmunt J, Théodore C, Demkov T, Komyakov B, Sengelov L, Daugaard G, Caty A, Charles J, Jagiello-Gruszfeld A, Karyakin O, Delgado FM, Hurteloup P, Winquist E, Morsli N, Salhi Y, Culine S and von der Maase H: Phase III trial of vinflunine plus best supportive care compared with best supportive care alone after a platinum-containing regimen in patients with advanced transitional cell carcinoma of the urothelial tract. Journal of Clinical Oncology 27: 4454-4461, 2009.

28 Bajorin DF, Dodd PM, Mazumdar M, Fazzari M, McCaffrey JA, Scher HI, Herr H, Higgins G and Boyle MG: Long-Term Survival in Metastatic Transitional-Cell Carcinoma and Prognostic Factors Predicting Outcome of Therapy. J Clin Oncol 17: 3173-3181, 1999.
Received March 23, 2017

Revised April 3, 2017

Accepted April 6, 2017 